\title{
The changes and factors associated with post- discharge self-care behaviors among Chinese patients with heart failure
}

This article was published in the following Dove Press journal:

Patient Preference and Adherence

9 November 2015

Number of times this article has been viewed

\author{
Xiaolin $\mathrm{Hu}^{\prime}$ \\ Xiuying $\mathrm{Hu}^{\prime}$ \\ Yonglin $\mathrm{Su}^{2}$ \\ Moying $\mathrm{Qu}^{3}$ \\ Mary A Dolansky ${ }^{4}$ \\ 'Department of Nursing, ${ }^{2}$ Department \\ of Rehabilitation Medicine, \\ ${ }^{3}$ Department of Cardiology, West \\ China Hospital, Sichuan University, \\ Chengdu, Sichuan, People's Republic \\ of China; ${ }^{4}$ Frances Payne Bolton \\ School of Nursing, Case Western \\ Reserve University, Cleveland, \\ $\mathrm{OH}$, USA
}

Correspondence: Yonglin Su

Department of Rehabilitation Medicine,

West China Hospital, Sichuan University,

37 Guo-xue-xiang Street, Chengdu,

Sichuan 61004I, People's Republic of China

$\mathrm{Tel}+868540340$ l

Fax +868540340I

Email daage@।63.com
Background: Self-care behavior is essential for achieving good outcomes among patients with heart failure. Understanding the factors associated with self-care over time is important for the provision of appropriate and targeted interventions. However, little is known regarding the changes and factors associated with post-discharge self-care behaviors among Chinese patients with heart failure.

Objective: To investigate the changes and factors of self-care behaviors during the first 3 months following discharge among patients with heart failure in the People's Republic of China.

Methods: A descriptive design with a convenience sample was utilized in this study. Patients $(\mathrm{N}=128)$ from two hospitals, West China Hospital and Angjin Hospital, in Chengdu, People's Republic of China, were recruited from June 2013 to June 2014. The instruments used in the study included the following: the Social Support Rating Scale, the Hospital Anxiety and Depression Scale, the Self-Efficacy for Managing Chronic Disease 6-Item Scale, and the European Heart Failure Self-Care Behaviour Scale. Multivariate linear regression analyses were used to identify the factors related to self-care behaviors at baseline, 1 month, and 3 months following discharge.

Results: Patients' self-care behaviors were poor and decreased significantly over time ( $F=4.09$, $P<0.05)$. The factors associated with self-care behaviors at baseline included the following: education level, comorbidities, and social support. The factors related to self-care behaviors at 1 and 3 months following discharge included the following: education level, comorbidities, social support, and self-efficacy. The variances in self-care behaviors attributed to these factors were $43 \%, 46 \%$, and $42 \%$ at baseline, 1 month, and 3 months following discharge, respectively.

Conclusion: Additional support should be provided to patients with heart failure with low educational levels and patients with multiple comorbidities. Follow-up, continuity of care, and family caregiver integration following discharge are necessary for the said patients to improve their self-care behaviors and obtain better outcomes.

Keywords: heart failure, patients, self-care behaviors, associated factors

\section{Introduction}

Heart failure (HF) is a group of complicated syndromes resulting in frequent hospitalizations, high mortality rates, and reduced quality of life. ${ }^{1}$ In the People's Republic of China, over four million patients are afflicted with $\mathrm{HF}^{2}{ }^{2}$ The readmission rate associated with $\mathrm{HF}$ has been as high as $58.4 \%$ in a year. ${ }^{3}$

In Western countries, HF readmissions are one of the primary causes of health care spending. ${ }^{4}$ Approximately $23 \%$ to $31 \%$ of readmissions may have been prevented via improved self-care, including improved medication adherence, early symptom recognition, and timely responses to escalating symptoms. ${ }^{5}$ Improvements in self-care among 
patients with HF are important with respect to patient outcomes. The effect of self-care on patients' health outcomes is comparable with that of medical therapy. ${ }^{6,7}$ Effective self-care behavior has been linked to better health status, reduced readmission rates, ${ }^{8}$ decreased mortality rates, ${ }^{8}$ and lower health care costs. ${ }^{9}$

In spite of the vital role played by self-care in the management of HF, many factors affect self-care among patients with $\mathrm{HF}$, including patient characteristics (eg, age, health literacy, socioeconomic status, symptoms, and comorbidities), ${ }^{10,11}$ social support, psychological status (eg, depression and anxiety), ${ }^{10,11}$ and self-efficacy. ${ }^{12}$ Additionally, a lack of discharge planning and follow-up, as well as inadequate patient and caregiver education, is associated with poor self-care. ${ }^{13,14}$ In the People's Republic of China, a single study from Beijing determined that social support and psychological status were the primary factors influencing self-care behaviors among patients with HF. ${ }^{15}$

The literature from Western countries has demonstrated that self-care behavior is essential for achieving good outcomes for patients with HF. ${ }^{8,9}$ However, self-care in both US and European populations with HF is not adequate. ${ }^{16}$ As self-care behaviors differ among diverse patient populations from different countries, ${ }^{17}$ it is important to understand self-care behaviors from a Chinese perspective. To date, little is known regarding the factors associated with self-care among Chinese patients with HF. Additionally, there is a lack of available studies exploring changes in self-care behaviors over time among post-discharge HF patients in the People's Republic of China. Understanding the factors associated with self-care over time is important with respect to the provision of appropriate and targeted interventions for HF populations at different time points as a means of improving their self-care behaviors. Therefore, the objectives of this study were to: 1) investigate the changes in self-care behaviors among patients with HF in the People's Republic of China at baseline (discharge), 1 month, and 3 months following discharge and 2) identify the factors (demographic characteristics, social support, self-efficacy, and psychological status) associated with self-care behaviors at the three follow-up time points.

\section{Study design}

A cross-sectional descriptive design with a convenience sample was utilized in this study. The current survey is a secondary analysis. The parent study was an intervention for patients with HF (funded by the Science and Technology Bureau of Chengdu 2014-RK00-00013-ZF). ${ }^{18}$ The current descriptive study could provide useful information for the development of the parent intervention study. The patients were recruited from two hospitals, West China Hospital and Angjin Hospital, in Chengdu, People's Republic of China. This study was approved by the Ethics Committees of Sichuan University and the two hospitals mentioned above (K2014041). Written informed consent was provided by all patients, who were informed that they could withdraw from the study at any time.

\section{Sample}

Patients with HF were recruited from June 2013 to June 2014. The inclusion criteria were as follows: 1 ) a primary diagnosis of HF for at least 6 months; 2) 18 years of age or older; 3) The New York Heart Association (NYHA) classifications I to III; 4) no major surgery within the last 6 months; and 5) ability to speak Chinese. Patients with mental disorders such as schizophrenia or major depression, as well as patients with severe cognitive impairment, were excluded. Patients with NYHA class IV HF were excluded due to the severity of their illness. In this study, we used the Mini-Mental Status Examination to assess the cognitive function of the potential participants. ${ }^{19}$ The cutoff points for the Chinese Mini-Mental Status Examination are based on the patients' educational level as follows: scores of less than 17 (illiteracy), 20 (primary school), and 24 (junior high school or above) were indicative of severe cognitive impairment. ${ }^{20}$

\section{Measures}

Patients' baseline data were collected upon discharge and included their demographic characteristics, social support, self-efficacy, and psychological statuses. The data at 1 and 3 months following discharge were collected at clinics and included the patients' social support, selfefficacy, and psychological status. We scheduled appointments with the participants via a telephone call prior to their visits. Clinical data were collected from the patients' medical records. The participants completed surveys; survey questions were read by the researchers and recorded for the patients who could not read or write due to either illiteracy or physical limitations. The participants who completed each survey received 10 Yuan ( 2 US dollars) as a reward.

The instruments used in this study were as follows: 1) A demographic survey; 2) the Social Support Rating Scale; 3 ) the Hospital Anxiety and Depression Scale (HADS); 4) the Self-Efficacy for Managing Chronic Disease 6-Item Scale (SES6G); and 5) the European Heart Failure Self-Care Behaviour Scale (EHFScBS). 


\section{Demographic questionnaire}

The demographic data collected included the following: sex, age, education level, marital status, employment, financial resources for treatment, monthly income, NYHA classification, duration of HF symptoms, and comorbidities.

\section{The social support rating scale}

Social support was measured using the 10-item Chinese Social Support Rating Scale, ${ }^{21}$ as well as three subscales, including objective support, subjective support, and the degree of social support utility. Higher scores were indicative of better support with total scores ranging from 0 to 66 . The scale has adequate reliability and validity among Chinese patients. ${ }^{22}$ The test-retest reliability coefficient and the internal consistency of the scale were 0.92 and $0.88-0.94$, respectively.

\section{The HADS}

The psychological statuses of the patients were measured using the 14-item HADS, ${ }^{23}$ as well as two 7-item subscales, including anxiety and depression. The HADS consists of a 4-point scale ranging from 0 , "not present," to 3 , "considerable." Higher scores were indicative of higher levels of symptoms, with total scores ranging from 0 to 21 for each subscale. A score of eight or above indicated that an individual suffered from probable symptoms of either anxiety or depression. The HADS has adequate reliability and validity. ${ }^{24}$ The Chinese version of the HADS has adequate reliability and validity among Chinese patients suffering from chronic diseases. $^{25}$

\section{The SES6G}

The patients' self-efficacy was measured using the SES6G, ${ }^{26}$ a self-reporting instrument designed to evaluate the degree of confidence for patients suffering from chronic disease as a means of managing their disease. The SES6G consists of a 10-point scale ranging from 0 , "not at all confident," to 10 , "totally confident." Higher scores were indicative of greater confidence in disease management, with total scores ranging from 0 to 60 . The scale has adequate reliability and validity. ${ }^{26,27}$ The Chinese version of the SES6G has adequate reliability and validity among Chinese patients suffering from chronic diseases. ${ }^{28}$

\section{The EHFScBS}

The self-care behaviors of patients with HF were evaluated using the 12-item EHFScBS. ${ }^{29}$ The EHFScBS consists of a 5-point scale ranging from 0 , "completely agree" to 4 , "completely disagree." Total scores ranged from 12 to 60 ; higher scores were indicative of worse self-care behaviors. The EHFScBS has adequate reliability and validity in diverse populations. ${ }^{30,31}$ The Chinese version of the EHFScBS has adequate reliability and validity among Chinese patients with $\mathrm{HF}^{32}$ The content validity index with the item and the scale of the Chinese version EHFScBS were 0.96 and 0.89, respectively, with Cronbach's alpha $0.82 .{ }^{32}$

\section{Data analysis}

The SPSS 17.0 statistical analysis package was used to analyze the data. Prior to analysis, data entry was checked twice by two researchers to ensure accuracy. Descriptive statistics were used to describe the patients' demographic and clinical data. Independent $t$-tests and one-way analyses of variance were used to detect self-care differences among subgroups of patients' characteristics. Correlation analyses were used to identify relationships among self-behaviors and social support, self-efficacy, and psychological status. Multivariate linear regression analyses were used to determine the factors associated with self-care behaviors and the degree of variances in self-care behaviors at baseline, 1 month, and 3 months following discharge. Significant variables from the univariate analyses and the correlation analyses were entered into the regression models as independent variables, and the self-care behavior scores were entered as dependent variables. All tests were two-tailed, and $P<0.05$ was considered statistically significant.

\section{Results}

Among 128 patients who agreed to participate in the study, five patients dropped out due to a change of residence (three) and changes in contact method (two) at 1 month following discharge, another patient withdrew due to physical reasons, and two patients declined to participate due to changes in their contact methods at 3 months following discharge. A total of 120 participants completed three sections of the surveys.

\section{Sample characteristics}

As shown in Table 1, the average age of the enrolled patients was 64.6 years $(\mathrm{SD}=14.8)$, and the age range was 23 to 86 years. More than half of the patients $(71.9 \%)$ were older than 60 years. The majority were men (59.4\%), and 103 patients $(80.5 \%)$ were married. More than half $(53.9 \%)$ had an educational level equivalent to primary school or below. More than half of the patients (58.6\%) were employed. The majority $(80.5 \%)$ had medical insurance or some other form of insurance for treatment. The majority $(81.2 \%)$ had 
Table I Characteristics of patients with HF at baseline $(\mathrm{N}=\mid 28)$

\begin{tabular}{|c|c|}
\hline Characteristics & $\mathbf{N}(\%)$ \\
\hline \multicolumn{2}{|l|}{ Sex } \\
\hline Male & $76(59.4)$ \\
\hline Female & $52(40.6)$ \\
\hline \multicolumn{2}{|l|}{ Age of patient (years) } \\
\hline$\leq 60$ & $36(28.1)$ \\
\hline $6 I-74$ & $52(40.6)$ \\
\hline$\geq 75$ & $40(31.3)$ \\
\hline \multicolumn{2}{|l|}{ Educational level } \\
\hline Primary school or below & $69(53.9)$ \\
\hline Junior high school & $26(20.3)$ \\
\hline Senior high school & $12(9.4)$ \\
\hline College or above & $21(16.4)$ \\
\hline \multicolumn{2}{|l|}{ Marital status } \\
\hline Married & $103(80.5)$ \\
\hline Spinsterhood/divorced/widowed & $25(19.5)$ \\
\hline \multicolumn{2}{|l|}{ Employed } \\
\hline Yes & $75(58.6)$ \\
\hline No & $53(41.4)$ \\
\hline \multicolumn{2}{|l|}{ Financial source for treatment } \\
\hline Medical insurance and other insurance & $103(80.5)$ \\
\hline Self-support & $25(19.5)$ \\
\hline \multicolumn{2}{|l|}{ Monthly income (in Yuan) } \\
\hline$\leq \mathrm{I}, 000$ & $20(15.6)$ \\
\hline $1,001-1,999$ & $37(28.9)$ \\
\hline $2,000-2,999$ & $47(36.7)$ \\
\hline$\geq 3,000$ & $24(18.8)$ \\
\hline \multicolumn{2}{|l|}{ NYHA classification } \\
\hline I & $41(32.0)$ \\
\hline ॥ & $65(50.8)$ \\
\hline III & $22(17.2)$ \\
\hline \multicolumn{2}{|l|}{ Duration of HF (years) } \\
\hline$<1$ & $56(43.8)$ \\
\hline$\geq 1$ & $72(56.2)$ \\
\hline \multicolumn{2}{|l|}{ Numbers of comorbidities of patients } \\
\hline$\leq 1$ & $41(32.0)$ \\
\hline 2 & $51(39.9)$ \\
\hline$\geq 3$ & $36(28.1)$ \\
\hline
\end{tabular}

Abbreviations: HF, heart failure; NYHA, New York Heart Association.

a monthly income of less than 3,000 Yuan (500 US dollars). NYHA Classification distributions among the patients were as follows: Class I, 41 patients (32.0\%); Class II, 65 patients (50.8\%); and Class III, 22 patients (17.2\%). Most of the patients $(56.2 \%)$ had suffered from HF for more than 1 year. The majority of patients $(68 \%)$ suffered from more than one comorbidity.

\section{Self-care behaviors among patients with HF}

As shown in Table 2, the patients' mean self-care behavior scores at baseline, 1 month, and 3 months following discharge were 28.56 ( $\mathrm{SD}=5.63), 28.82(\mathrm{SD}=5.57)$, and $30.41(\mathrm{SD}=5.58)$, respectively. The self-care behavior scores
Table 2 Changes in scores of self-care at three time points

\begin{tabular}{|c|c|c|c|c|}
\hline Time & $\mathbf{n}$ & $\begin{array}{l}\text { Self-care } \\
\text { Mean (SD) }\end{array}$ & $\boldsymbol{F}$ & $P$-value \\
\hline Baseline & 128 & $28.56(5.63)$ & 4.090 & $0.017^{*}$ \\
\hline I month following discharge & 123 & $28.82(5.57)$ & & \\
\hline 3 months following discharge & 120 & $30.4 I(5.58)$ & & \\
\hline \multicolumn{5}{|c|}{$\begin{array}{l}\text { Note: } * P<0.05 \text {. } \\
\text { Abbreviation: } F \text {, statistic from an analysis of variance. }\end{array}$} \\
\hline \multicolumn{5}{|c|}{$\begin{array}{l}\text { increased significantly over time }(F=4.09, P=0.017) \text {. Higher } \\
\text { scores on the EHFScBS were indicative of worse self-care } \\
\text { behaviors. The participants' self-care behaviors decreased } \\
\text { during the follow-up period. The worst self-care behavior } \\
\text { time point occurred at } 3 \text { months following discharge. }\end{array}$} \\
\hline
\end{tabular}

The univariate analyses demonstrated that there were significant relationships between the self-care behaviors and the characteristics of the patients, including age, education level, monthly family income, and comorbidities (Table 3). Additionally, patients of older age, with lower education levels, lower monthly incomes, and higher numbers of comorbidities exhibited higher scores on the EHFScBS, indicating worse self-care behaviors (Table 3 ).

\section{A correlation analysis of self-care behaviors and social support, self- efficacy, and psychological status}

A Pearson correlation analyses demonstrated the existence of a significant inverse relationship among self-care behavior scores and social support and self-efficacy at baseline, 1 month, and 3 months following discharge. However, there were no significant relationships between self-care behavior scores and psychological status at any of the three time points (Table 4).

\section{A multivariate regression analysis of the patients' self-care behaviors}

Three multivariate linear regression analyses were used to determine the factors associated with the patients' self-care behaviors at the aforementioned three follow-up points. The EHFScBS scores served as dependent variables. The significant variables in the univariate and correlation analyses, including the ages of patients, patients' education levels, monthly family income, numbers of comorbidities, social support, and self-efficacy at the different time points, were entered into the model as independent variables. As shown 
Table 3 Significant differences in self-care behaviors in the patients' subgroups at three time points

\begin{tabular}{|c|c|c|c|}
\hline $\begin{array}{l}\text { Characteristics of } \\
\text { patients }\end{array}$ & $\begin{array}{l}\text { Self-care }\left(T_{0}\right) \\
\text { Mean }(S D) \\
(n=\mid 28)\end{array}$ & $\begin{array}{l}\text { Self-care }\left(T_{1}\right) \\
\text { Mean (SD) } \\
(n=\mid 23)\end{array}$ & $\begin{array}{l}\text { Self-care }\left(T_{2}\right) \\
\text { Mean (SD) } \\
(n=\mid 20)\end{array}$ \\
\hline \multicolumn{4}{|l|}{ Age } \\
\hline$\leq 60$ & $23.86(5.76)$ & $24.80(6.39)$ & $26.00(5.54)$ \\
\hline $6 I-74$ & $28.43(5.62)$ & $28.55(5.44)$ & $30.35(5.52)$ \\
\hline$\geq 75$ & $29.06(3.29)$ & $29.63(4.13)$ & $31.00(3.46)$ \\
\hline$F$ & $7.96 * *$ & $6.09 *$ & $6.87^{*}$ \\
\hline \multicolumn{4}{|l|}{ Educational level } \\
\hline Primary school or below & $31.04(4.33)$ & $31.32(4.32)$ & $32.65(4.39)$ \\
\hline Junior high school & $27.4 \mathrm{I}(5.05)$ & $27.81(5.14)$ & $29.64(5.54)$ \\
\hline Senior high school & $24.75(4.5 \mathrm{I})$ & $25.16(4.32)$ & $27.08(4.72)$ \\
\hline College or above & $24.00(6.43)$ & $24.02(5.95)$ & $25.90(5.99)$ \\
\hline$F$ & $|4.9|^{* *}$ & 16.06 ** & $12.49 * *$ \\
\hline \multicolumn{4}{|c|}{ Monthly family income (in Yuan) } \\
\hline$\leq 1,000$ & $32.00(1.09)$ & $32.67(1.96)$ & $34.16(1.47)$ \\
\hline $1,001-1,999$ & $31.67(3.75)$ & $31.44(3.39)$ & $33.17(3.45)$ \\
\hline $2,000-2,999$ & $31.30(4.14)$ & $31.30(4.10)$ & $32.85(4.69)$ \\
\hline$\geq 3,000$ & $27.43(5.85)$ & $27.55(5.58)$ & $29.46(5.67)$ \\
\hline$F$ & $5.56 * *$ & $4.52^{* *}$ & $4.83^{* *}$ \\
\hline \multicolumn{4}{|l|}{ Numbers of comorbidities } \\
\hline$\leq 1$ & $24.45(5.3 \mathrm{I})$ & $25.24(5.56)$ & $26.63(5.30)$ \\
\hline 2 & $28.57(3.23)$ & $28.43(3.37)$ & $30.13(3.69)$ \\
\hline$\geq 3$ & $32.75(0.96)$ & $33.25(1.25)$ & $34.75(2.21)$ \\
\hline$F$ & $39.84 * *$ & $33.27 * *$ & $33.48 * *$ \\
\hline
\end{tabular}

Note: $* P<0.05, * * P<0.01$.

Abbreviations: $F$, statistic from an analysis of variance; $T_{0}$, at baseline; $T_{1}, I$ month after discharge; $T_{2}, 3$ months after discharge; $S D$, standard deviation.

in Table 5, at baseline, patients' education levels $(b=-0.310$, $P<0.01$ ), numbers of comorbidities ( $b=0.359, P<0.01$ ), and social support $(b=-0.487, P<0.01$ ) correlated significantly with self-care behavior. In all, $43 \%$ of the variances in selfcare behavior were explained by these factors. At 1 and

Table 4 Correlation analyses of self-care behaviors and social support, self-efficacy, and psychological status at three time points

\begin{tabular}{llll}
\hline Variables & \multicolumn{3}{l}{ Scores of self-care behaviors } \\
\cline { 2 - 4 } & $\mathbf{T}_{0}$ & $\mathbf{T}_{1}$ & $\mathbf{T}_{2}$ \\
\hline Social support $\left(\mathrm{T}_{0}\right)$ & $-0.474^{* *}$ & $-0.469^{* *}$ & $-0.492^{* *}$ \\
Social support $\left(\mathrm{T}_{1}\right)$ & $-0.459^{* *}$ & $-0.366^{* *}$ & $-0.368^{* *}$ \\
Social support $\left(\mathrm{T}_{2}\right)$ & $-0.456^{* *}$ & $-0.46 \mathrm{I}^{* *}$ & $-0.383^{* *}$ \\
Self-efficacy $\left(\mathrm{T}_{0}\right)$ & $-0.379^{* *}$ & $-0.313^{* *}$ & $-0.33 \mathrm{I}^{* *}$ \\
Self-efficacy $\left(\mathrm{T}_{1}\right)$ & $-0.403^{* *}$ & $-0.388^{* *}$ & $-0.46 \mathrm{I}^{* *}$ \\
Self-efficacy $\left(\mathrm{T}_{2}\right)$ & $-0.40 \mathrm{I}^{* *}$ & $-0.44 \mathrm{I}^{* *}$ & $-0.450^{* *}$ \\
Depression $\left(\mathrm{T}_{0}\right)$ & 0.042 & 0.027 & 0.009 \\
Depression $\left(\mathrm{T}_{1}\right)$ & 0.033 & 0.036 & 0.007 \\
Depression $\left(\mathrm{T}_{2}\right)$ & 0.045 & 0.037 & 0.034 \\
Anxiety $\left(\mathrm{T}_{0}\right)$ & 0.044 & 0.040 & 0.010 \\
Anxiety $\left(\mathrm{T}_{1}\right)$ & 0.032 & $0.03 \mathrm{I}$ & 0.015 \\
Anxiety $\left(\mathrm{T}_{2}\right)$ & 0.050 & 0.038 & 0.032 \\
\hline Note: & & &
\end{tabular}

Note: $* * p<0.01$.

Abbreviations: $T_{0}$, at baseline; $T_{1}, I$ month following discharge; $T_{2}, 3$ months following discharge.
3 months following discharge, however, patients' education levels $(b=-0.197, P<0.01 ; b=-0.171, P<0.01)$, numbers of comorbidities $(b=0.202, P<0.01 ; b=0.255, P<0.01)$, social support $(b=-0.386, P<0.01 ; b=-0.287, P<0.01)$, and self-efficacy $(b=-0.356, P<0.01 ; b=-0.401, P<0.01)$

Table 5 Multivariate analysis of the patients' self-care behaviors at three time points $(\mathrm{N}=128)$

\begin{tabular}{|c|c|c|c|c|c|}
\hline & B & SE & $\mathbf{B}^{*}$ & $t$ & $P$-value \\
\hline \multicolumn{6}{|l|}{ Factors at $T_{0}(n=\mid 28)$} \\
\hline Educational level & -2.056 & 0.384 & -0.310 & -5.349 & $0.000^{* *}$ \\
\hline Numbers of comorbidities & 2.154 & 0.324 & 0.359 & 6.641 & $0.000^{* *}$ \\
\hline Social support & -0.344 & 0.037 & -0.487 & -9.254 & $0.000^{* *}$ \\
\hline \multicolumn{6}{|l|}{ Factors at $T_{1}(n=123)$} \\
\hline Educational level & -1.293 & 0.387 & -0.197 & -3.341 & $0.00 I^{* *}$ \\
\hline Numbers of comorbidities & 1.197 & 0.327 & 0.202 & 3.662 & $0.000^{* *}$ \\
\hline Social support & -0.277 & 0.039 & -0.386 & -7.185 & $0.000^{* *}$ \\
\hline Self-efficacy & -1.668 & 0.291 & -0.356 & -5.735 & $0.000^{* *}$ \\
\hline \multicolumn{6}{|l|}{ Factors at $T_{2}(n=\mid 20)$} \\
\hline Educational level & -1.120 & 0.419 & $-0.17 \mid$ & -2.676 & $0.009 * *$ \\
\hline Numbers of comc & 1.513 & 0.356 & 0.255 & 4.248 & $0.000^{* *}$ \\
\hline Social support & -0.201 & 0.040 & -0.287 & -4.996 & $0.000^{* *}$ \\
\hline Self-efficacy & -1.915 & 0.302 & -0.401 & -6.343 & $0.000^{* *}$ \\
\hline
\end{tabular}


correlated significantly with self-care behaviors. At both 1 and 3 months following discharge, the variances in selfcare behaviors accounted for by these factors were $46 \%$ and $42 \%$, respectively (Table 5).

\section{Discussion}

We observed that the EHFScBS scores in Southwest China were higher than those noted in a previous study in a Western country, ${ }^{30}$ a finding indicative of worse self-care behavior in our sample. Culture plays an important role in the development of self-care practices. ${ }^{33}$ Individuals' experiences, perceptions, and behaviors during an illness are influenced by cultural norms. ${ }^{34}$ The poor self-care behavior observed in our sample may have been related to the sick role, ${ }^{35}$ as Chinese patients are passive recipients of care as opposed to active participants and are more likely be dependent on health care providers and family caregivers..$^{35,36}$ The provision of care and aid for an ill family member is of greater importance than self-care; therefore, patients may ignore the importance of self-care. Meanwhile, self-care behavior is poorer among patients with $\mathrm{HF}$ in developing countries compared with developed countries due to insufficient resources. ${ }^{37}$ Our study was conducted in an underdeveloped district of Southwest China. Therefore, a lack of resources may have resulted in poorer self-care behaviors, as well as a poor awareness and understanding of HF, among Chinese patients. ${ }^{38}$ For example, most patients have never gotten a flu shot and believe that daily weight monitoring makes no sense. ${ }^{15}$ The majority of the patients enrolled in this study had no education beyond primary school. Low education levels may also explain the poor self-care behaviors noted in our sample, as discussed later. Given these findings, cultural values must be incorporated into self-care education. Health providers must provide education for both patients and caregivers to enhance their understanding of the importance of self-care. Knowledge and skills are also essential for the performance of successful self-care. Additionally, health providers should recommend and guide appropriate self-care regimens for both patients and their caregivers after assessing the said patients' abilities and available resources.

Additionally, we observed that our patients' self-care behaviors declined significantly during the first 3-month following discharge. The best and worst self-care behaviors were observed at baseline and 3 months following discharge, respectively. Although there was a significant difference between these results, their clinical significance is questionable. However, the results are similar to those of a previous study conducted in Beijing. ${ }^{15}$ The better self-care behaviors at baseline may be attributed to the health education provided to patients both during their hospitalizations and upon discharge. In the People's Republic of China, patients do not obtain transitional care services following discharge. Therefore, they are more likely to ignore the importance of self-care without the supervision and assistance of medical care providers following discharge. The findings of this study are reminders of the necessity of promoting self-care behaviors following discharge. The strategies intended to improve self-care behaviors include nursing education and skill training during the follow-up period.

Education level was associated with self-care behavior in this study. Patients with higher education levels exhibited better self-care behaviors compared with patients with lower education levels. These findings were consistent with those of previous studies. ${ }^{37,39}$ Higher education levels are associated with better learning capabilities and superior recognition of worsening symptoms. ${ }^{40}$ Additionally, higher education levels are linked to high self-efficacy with respect to the ability to adhere to self-care regimens; ${ }^{39}$ therefore, patients with higher education levels may more easily engage in selfcare and comply with regimens consistently compared with patients with poorer education. In our sample, the majority of the patients were older than 60 years of age and had a primary school education or below. Additional education and interventions are necessary to improve these patients' selfcare behaviors. Given the interdependence noted above, an excellent strategy with which to improve self-care behaviors entails the inclusion of family caregivers as they may have the power to facilitate self-care regimens.

The number of comorbidities was associated with selfcare behavior at all three time points. The patients with more comorbidities exhibited poorer self-care behaviors, findings that are similar to those of prior studies. ${ }^{41,42}$ The presence of multiple comorbidities makes it difficult for patients to differentiate symptoms of HF from those of other comorbidities, which may result in a delay in seeking medical assistance for worsening sypmtoms. ${ }^{36,43}$ Additionally, patients with more comorbidities may be more frustrated by the additional costs and increased requirements of selfcare compared with patients with fewer comorbidities. ${ }^{36,43}$ In our sample, the majority of our patients had at least one comorbidity. Therefore, it is important for medical providers to help patients recognize the symptoms of existing comorbidities beyond HF. Additionally, as it is difficult for patients to distinguish the symptoms of HF from those of other comorbidities, telemetry and other types of follow-up are effective supplements to self-care in terms of safety for patients suffering from multiple comorbidities. ${ }^{36}$ 
Social support had correlated positively with self-care behaviors, a finding similar to those of previous studies. ${ }^{44,45}$ The patients receiving higher levels of social support exhibited better self-care behaviors. Social support from family and close friends contributes to the development of self-care skills among patients with $\mathrm{HF} .{ }^{46}$ Additionally, social support exerts positive effects on coping with stress,${ }^{47}$ medication compliance, ${ }^{44}$ and dietary adherence ${ }^{48}$ Enhancing social support is an effective means of maximizing self-care. Due to the absence of sufficient medical resources in the People's Republic of China, the primary support offered to patients following discharge is emotional support from family caregivers. Although family caregivers play an important role in disease management in the People's Republic of China, knowledge regarding HF is poor among Chinese family caregivers ${ }^{49}$ that may reduce the quality of the support provided to patients. ${ }^{50}$ Therefore, health care providers should provide family caregivers with the knowledge and skills necessary to care for patients with HF. The strategies promoting social support include offering continuity of care and providing support groups.

We observed that self-efficacy was associated with self-care behaviors at 1 and 3 months following discharge; however, there was no significant correlation between selfefficacy and self-care at discharge, which may be explained by the fact that patients improve their self-care during their hospitalizations via various resources, including doctors, nurses, and other medical staff. However, a significant relationship was observed between self-efficacy and self-care at both 1 and 3 months following discharge. The patients with high self-efficacy exhibited better self-care behaviors, a finding that was consistent with those of other studies. ${ }^{39,51}$ Selfefficacy may influence medication adherence and responses to stress. ${ }^{39}$ Patients with high self-efficacy are confident in their abilities and are more likely to engage in and adhere to self-care regimens in spite of obstacles. ${ }^{52}$ The findings of this study indicate that it is important for medical staff members to enhance patients' self-care behaviors to improve their self-efficacy during the transition from the hospital to home. The strategies intended to promote self-efficacy include the following: patients experiencing personal success, providing patients with peer role models, and educating both patients and caregivers. Medical care providers must utilize these hands-on strategies to improve patients' self-efficacy.

Another finding of our study was that there was no significant relationship among self-care behaviors, anxiety, and depression, which was inconsistent with the results of previous studies. ${ }^{10,11}$ The discrepancies may be related to sample inclusion. Patients with NYHA class IV HF were excluded from this study because of the severity of their symptoms, as they are different from the patients with NYHA classes I to III HF. Additionally, patients with NYHA class IV HF may suffer from more anxiety and depressive symptoms compared with patients with NYHA classes I to III HF. Therefore, our inclusion criteria may have affected our results. Additional studies are warranted to determine the relationship among self-care behaviors, anxiety, and depression among Chinese patients with HF.

\section{Limitations}

This study was limited by the use of a convenience sample recruited from only two hospitals in Chengdu, which may have affected the sample's representativeness. Another limitation was that our 3-month follow-up period provided information regarding only short-term changes in self-care behavior. Moreover, other potential variables such as cognitive function and family relationships must be included as these may also affect self-care behavior. Self-reporting and recall bias were also limitations of this study and must therefore be considered when interpreting our results.

\section{Conclusion}

In summary, this study provided information regarding self-care behaviors among patients with HF in the People's Republic of China. According to our findings, self-care behaviors among the said patients were poor and declined significantly over time following discharge. Low education levels, more comorbidities, and low social support were associated with poor self-care behaviors at baseline, 1 month, and 3 months following discharge. Meanwhile, low self-efficacy was associated with poor self-care behaviors at both 1 and 3 months following discharge. For patients with HF with low education levels and multiple comorbidities, additional instructional support and follow-up are warranted. Meanwhile, strategies designed to improve patients' self-efficacy and social support such as providing continuity of care following discharge and offering support groups are potential areas in which to promote self-care behaviors. Given the interdependence commonly observed in the People's Republic of China, family caregivers should be included in self-care regimens to maximize the said regimens' benefits.

\section{Acknowledgments}

The study was funded by the Science and Technology Bureau of Chengdu (2014-RK00-00013-ZF). The authors would like to thank the executives and participating staff of the two hospitals, West China Hospital and Angjin Hospital, 
Chengdu, People's Republic of China, for their support and assistance. Special thanks are given to all the participants for their understanding and cooperation.

\section{Disclosure}

The authors report no conflicts of interest in this work.

\section{References}

1. Lloyd-Jones D, Adams R, Carnethon M, et al. Heart disease and stroke statistics - 2009 update: a report from the American Heart Association Statistics Committee and Stroke Statistics Subcommittee. Circulation. 2009;119:410-528.

2. Gu DF, Huang GY, He J, Wu XG, Duan XF. Investigation of prevalence and distributing feature of chronic heart failure in Chinese adult population. Chin J Cardiol. 2003;31:3-6. [Chinese.]

3. Xue L, Zhou JL, Wang AP. Analysis and strategies of influence factors of hospitalization of patients with chronic heart failure. Med Res Educ. 2009;26:80-82. [Chinese.]

4. Liao L, Anstrom KJ, Gottdiener JS, et al. Long-term costs and resource use in elderly participants with congestive heart failure in the cardiovascular health study. Am Heart J. 2007;153(2):245-252.

5. Annema C, Luttik ML, Jaarsma T. Reasons for readmission in heart failure: perspectives of patients, caregivers, cardiologists, and heart failure nurses. Heart Lung. 2009;38(5):427-434.

6. McDonald K. Disease management programs for heart failure. Curr Treat Options Cardiovasc Med. 2010;12(6):578-586.

7. Savard LA, Thompson DR, Clark AM. A meta-review of evidence on heart failure disease management programs: the challenges of describing and synthesizing evidence on complex interventions. Trials. 2011; 12(1):194

8. Van der Wal MH, van Veldhuisen DJ, Veeger NJ, Rutten FH, Jaarsma T. Compliance with non-pharmacological recommendations and outcome in heart failure patients. Eur Heart J. 2010;31(12):1486-1493.

9. Lorig KR, Holman HR. Self-management education: history, definition, outcomes, and mechanisms. Ann Behav Med. 2003;26(1):1-7.

10. Riegel B, Moser DK, Anker SD, et al. State of the science promoting self-care in persons with heart failure: a scientific statement from the American Heart Association. Circulation. 2009;120(12):1141-1163.

11. Moser DK, Watkins JF. Conceptualizing self-care in heart failure: a life course model of patient characteristics. J Cardiovasc Nurs. 2008; 23(3):205-218.

12. Riegel B, Lee CS, Dickson VV, Carlson B. An update on the self-care of heart failure index. J Cardiovasc Nurs. 2009;24(6):485-497.

13. Tsuchihashi M, Tsutsui H, Kodama K, et al. Medical and socioenvironmental predictors of hospital readmission in patients with congestive heart failure. Am Heart J. 2001;142(4):20A-26A.

14. Grady KL, Dracup K, Kennedy G, et al. Team management of patients with heart failure: a statement for healthcare professionals from the Cardiovascular Nursing Council of the American Heart Association. Circulation. 2000;102(19):2443-2456.

15. Shao X, Li Z, Shun H. Study on the self-care behaviors in chronic heart failure patients. Chin J Nurs. 2009;45(7):648-650. [Chinese.]

16. Artinian NT, Magnan M, Sloan M, Lange MP. Self-care behaviors among patients with heart failure. Heart Lung. 2002;31(3):161-172.

17. Jaarsma T, Strömberg A, Gal TB, et al. Comparison of self-care behaviors of heart failure patients in 15 countries worldwide. Patient Educ Couns. 2013;92(1):114-120.

18. Science and Technology Bureau of Chengdu [homepage]. Available from: http://www.cdst.gov.cn/. Accessed October 13, 2015. Chinese.

19. Folstein MF, Folstein SE, McHugh PR. "Mini-mental state". A practical method for grading the cognitive state of patients for the clinician. J Psychiatr Res. 1975;12(3):189-198.

20. Zhang MY, Katzman R, Salmon D, et al. The prevalence of dementia and Alzheimer's disease in Shanghai, China: impact of age, gender, and education. Ann Neurol. 1990;27(4):428-437.
21. Xiao SY. Theory basis and application study of social support scale. J Clin Psychiatry. 1994;4(2):98-100. [Chinese.]

22. Liu JW, Li FY, Lian YL. Investigation of reliability and validity of the social support scale. J Xinjiang Med Univ. 2008;31(1):1-3. [Chinese.]

23. Zigmond AS, Snaith R. The hospital anxiety and depression scale. Acta Psychiatr Scand. 1983;67(6):361-370.

24. Bjelland I, Dahl AA, Haug TT, Neckelmann D. The validity of the hospital anxiety and depression scale. An updated literature review. J Psychosom Res. 2002;52(2):69-78.

25. Qian J, Bian CD, Cui HD, Wu WY, Li CB. Comparative study of reliability and validity between several screening scales of anxiety. J Intern Med Concepts Pract. 2011;6(3):176-179. [Chinese.]

26. Lorig KR, Sobel DS, Ritter PL, Laurent D, Hobbs M. Effect of a selfmanagement program on patients with chronic disease. Eff Clin Pract. 2000;4(6):256-262.

27. Freund T, Gensichen J, Goetz K, Szecsenyi J, Mahler C. Evaluating selfefficacy for managing chronic disease: psychometric properties of the six-item self-efficacy scale in Germany. J Eval Clin Pract. 2013;19(1): 39-43.

28. Zhang H, Zhao QH. Investigation on factors associated with health behavior of patients with coronary stent implantation. Chin J Nurs. 2008;43(6):513-515. [Chinese.]

29. Jaarsma T, Strömberg A, Mårtensson J, Dracup K. Development and testing of the European heart failure self-care behaviour scale. Eur $J$ Heart Fail. 2003;5(3):363-370.

30. González B, Lupón J, Parajón T, Urrutia A, Herreros J, Valle V. Use of the European Heart Failure Self-care Behaviour Scale (EHFScBS) in a heart failure unit in Spain. Rev Esp Cardiol. 2006;59(2):166-170.

31. Kato N, Ito N, Kinugawa K, Kazuma K. Validity and reliability of the Japanese version of the European Heart Failure Self-Care Behavior Scale. Eur J Cardiovasc Nurs. 2008;7(4):284-289.

32. Yu DSF, Lee DTF, Thompson DR, Jaarsma T, Woo J, Leung EMF. Psychometric properties of the Chinese version of the European Heart Failure Self-Care Behaviour Scale. Int J Nurs Stud. 2011;48(4):458-467.

33. Becker G, Gates R, Newsom E. Self-care among chronically ill African Americans: culture, health disparities, and health insurance status. Am J Public Health. 2004;94(12):2066-2073.

34. Kleinman A. Patients and Healers in the Context of Culture. Berkeley: University of California Press; 1980.

35. Griva K, Ng HJ, Loei J, Mooppil N, McBain H, Newman SP. Managing treatment for end-stage renal disease - a qualitative study exploring cultural perspectives on facilitators and barriers to treatment adherence. Psychol Health. 2012;28(1):13-29.

36. Moser DK, Dickson V, Jaarsma T, Lee C, Stromberg A, Riegel B. Role of self-care in the patient with heart failure. Curr Cardiol Rep. 2012; 14(3):265-275.

37. Riegel B, Driscoll A, Suwanno J, et al. Heart failure self-care in developed and developing countries. J Card Fail. 2009;15(6):508-516.

38. Xue J, Chen GH, Ying XL, Shao SY. Relationship between self-care behavior and knowledge of heart failure. Appl J Gen Pract. 2007;5(3): 209-210. [Chinese.]

39. Chen AM, Yehle KS, Albert NM, et al. Relationships between health literacy and heart failure knowledge, self-efficacy, and self-care adherence. Res Social Adm Pharm. 2014;10(2):378-386.

40. Sui X, Gheorghiade M, Zannad F, Young JB, Ahmed A. A propensity matched study of the association of education and outcomes in chronic heart failure. Int J Cardiol. 2008;129(1):93-99. [Chinese.]

41. Chriss PM, Sheposh J, Carlson B, Riegel B. Predictors of successful heart failure self-care maintenance in the first three months after hospitalization. Heart Lung. 2004;33(6):345-353.

42. Dickson VV, Buck H, Riegel B. Multiple comorbid conditions challenge heart failure self-care by decreasing self-efficacy. Nurs Res. 2013; 62(1):2-9.

43. Dickson VV, Buck H, Riegel B. A qualitative meta-analysis of heart failure self-care practices among individuals with multiple comorbid conditions. J Card Fail. 2011;17(5):413-419.

44. DiMatteo MR. Social support and patient adherence to medical treatment: a meta-analysis. Health Psychol. 2004;23(2):207-218. 
45. Sayers SL, Riegel B, Pawlowski S, Coyne JC, Samaha FF. Social support and self-care of patients with heart failure. Ann Behav Med. 2008; 35:70-79.

46. Dunbar SB, Clark PC, Quinn C, Gary RA, Kaslow NJ. Family influences on heart failure self-care and outcomes. J Cardiovasc Nurs. 2008; 23(3):258-265.

47. Cohen S. Social relationships and health. Am Psychol. 2004;59(8): 676-684.

48. Dunbar SB, Clark PC, Deaton C, Smith AL, De AK, O’Brien MC. Family education and support interventions in heart failure: a pilot study. Nurs Res. 2005;54(3):158-166.

49. Qian HL, Wang JQ, Miu AF, Yu YM. Self-care level of patients with chronic heart failure and the administrative behaviors of their caregivers. Chin J Nurs. 2013;20(3):162-169. [Chinese].
50. Luttik ML, Jaarsma T, Moser D, Sanderman R, van Veldhuisen DJ The importance and impact of social support on outcomes in patients with heart failure: an overview of the literature. J Cardiovasc Nurs. 2005;20(3):162-169.

51. Riegel B, Dickson VV. A situation-specific theory of heart failure selfcare. J Cardiovasc Nurs. 2008;23(3):190-196.

52. Yehle KS, Plake KS. Self-efficacy and educational interventions in heart failure: a review of the literature. J Cardiovasc Nurs. 2010;25(3) 175-188.

\section{Publish your work in this journal}

Patient Preference and Adherence is an international, peer-reviewed, open access journal that focuses on the growing importance of patient preference and adherence throughout the therapeutic continuum. Patient satisfaction, acceptability, quality of life, compliance, persistence and their role in developing new therapeutic modalities and compounds to optimize clinical outcomes for existing disease states are major areas of interest for the journal. This journal has been accepted for indexing on PubMed Central. The manuscript management system is completely online and includes a very quick and fair peer-review system, which is all easy to use. Visit http://www. dovepress.com/testimonials.php to read real quotes from published authors.

\footnotetext{
Submit your manuscript here: http://www.dovepress.com/patient-preference-and-adherence-journal
} 